\title{
The Implications of Household PV-Battery Systems for Utilities in Thailand
}

\author{
Aksornchan Chaianong, Athikom Bangviwat, and Christoph Menke
}

\begin{abstract}
Driven by decreasing PV and battery installation costs and mismatch between household demand and PV generation, household PV-battery systems are going to be deployed in the country and create significant implications for utilities in Thailand. This paper mainly discusses both negative and positive impacts of household PV-battery systems on Thai utilities. The use of household batteries (storing excess generation from PV during daytime and discharging it in the evening) can increase solar capacity values and energy values to power system, mitigate the problem of "duck curve" and decrease PV integration cost. Household customers can consume more PV electricity (increasing PV self-consumption ratio) from the inclusion of batteries. As a result, it leads to higher revenue losses and lower re-sale of exported electricity from PV to distribution utilities, while it is not the case for generation/transmission utilities since re-sale of exported electricity is only relevant to distribution power system and revenue losses of generation/transmission utilities remain unchanged. This is because with household batteries, the level of PV installation is the same (only shifting the consumption of household PV excess generation from daytime to evening). Therefore, it is necessary to precisely quantify each cost and benefit component in order to understand values of household batteries to the power system.
\end{abstract}

Index Terms-Rooftop PV, battery, household, utility, Thailand.

\section{INTRODUCTION}

Among many available options of renewable energy resource in Thailand, solar photovoltaic (PV) energy has potentials for mitigating conventional source depletion and increasing domestic energy security [1]. Based on the public data from Thailand's Energy Regulatory Commission (ERC) and GIZ publication [2], as of 2017, installed solar PV capacity was around 3,200 MW (around 95\% for ground-mounted PV and 5\% for rooftop PV). There is a high share of ground-mounted PV due to previous government financial supports as summarized in [2]. However, driven by decreasing rooftop PV installation cost, many utility customers are interested in investing in rooftop PV and becoming "prosumers". This means they would both

Manuscript received on January 21, 2019; revised March 26, 2019. The authors would like to express their gratitude to the Joint Graduate School of Energy and Environment, King Mongkut's University of Technology Thonburi, and the Center of Excellence on Energy Technology and Environment, PERDO, Bangkok, Thailand, as well as the Petchra Pra Jom Klao Doctoral Degree Research Scholarship from King Mongkut's University of Technology Thonburi for financial supports.

The authors are with the Joint Graduate School of Energy and Environment, King Mongkut's University of Technology Thonburi, Bangkok, Thailand and Center of Excellence on Energy Technology and Environment, PERDO, Bangkok, Thailand (e-mail: achaianong@gmail.com, athikom.bangviwat@outlook.com,c.menke@blv.hochschule-trier.de ). generate and consume electricity. Based on [3], household customers are expected to share the highest percentage of PV adoption in the country due to their highest number of customers. However, due to a mismatch between household load profile and PV generation profile, household customers are able to consume limited PV electricity during daytime, leading to high surplus PV electricity to the grid that might cause grid stability issues as discussed in [4]. One of alternative ways to increase PV self-consumption ratio is to install a battery with a rooftop PV system. As discussed in various literatures on battery cost reduction (i.e. [5]-[7]) and some international experiences on battery deployment (i.e. [4], [8]), household PV-battery investment would become economically attractive in near future, leading to significant implications for utilities. Therefore, this paper aims to address implications of household PV-battery systems for Thai utilities in order to visualize both positive and negative economic impacts on utility businesses.

In Thailand, there are three utilities, which are (1) Electricity Generating Authority (EGAT); (2) Metropolitan Electricity Authority (MEA) and (3) Provincial Electricity Authority (PEA). MEA and PEA are distribution utilities. MEA is responsible for Bangkok and two neighboring provinces (Nonthaburi and Samut Prakarn), while PEA is responsible for the rest of the country. For EGAT, they are responsible for generation and transmission system. It is also important to note that there are other private producers in generation system, but only EGAT owns the whole transmission system in Thailand.

\section{HOUSEHOLD PV-BATTERY SYSTEMS}

Typically, household customers in Thailand have low electricity demand during the day when PV generation peaks as illustrated in Fig. 1. These are examples of a rooftop PV installation of $5 \mathrm{~kW}$ and modified load profiles to have a proper PV-to-load ratio as suggested in [9]. The PV generation profiles was simulated from the System Advisor Model (SAM), developed by the National Renewable Energy Laboratory (NREL) in the U.S ${ }^{1}$. It is clearly found that there would be PV excess generation during daytime. Household customers in PEA consume less electricity than MEA customers do. Thus, with the same PV system size, it leads to higher PV excess generation to the grid. With the use of battery, this amount of excess electricity from PV can be stored during the day and consumed in the evening when there are high demands. Therefore, a PV self-consumption ratio would increase. However, this situation would happen only when PV-battery system is more economically attractive

All assumptions were taken as same as [3] 
than PV-only system. It means battery installation cost needs to be low enough to make such an investment viable.

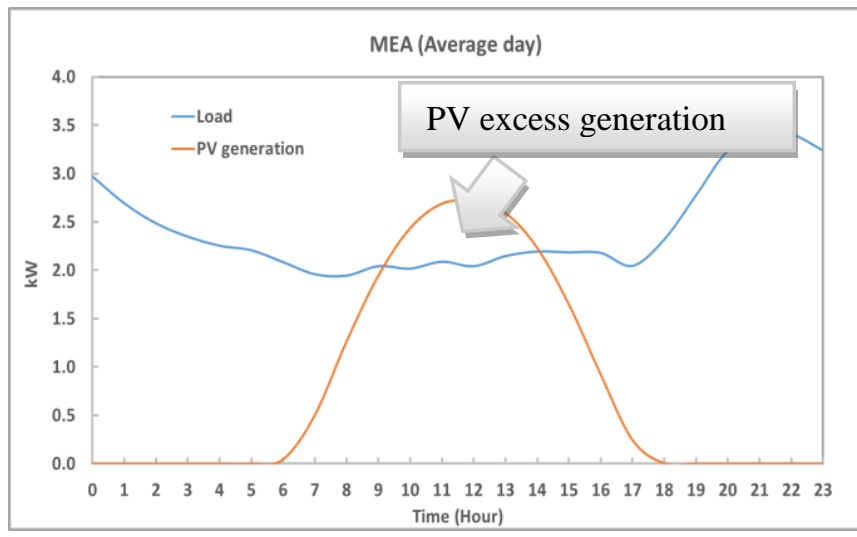

(a) MEA

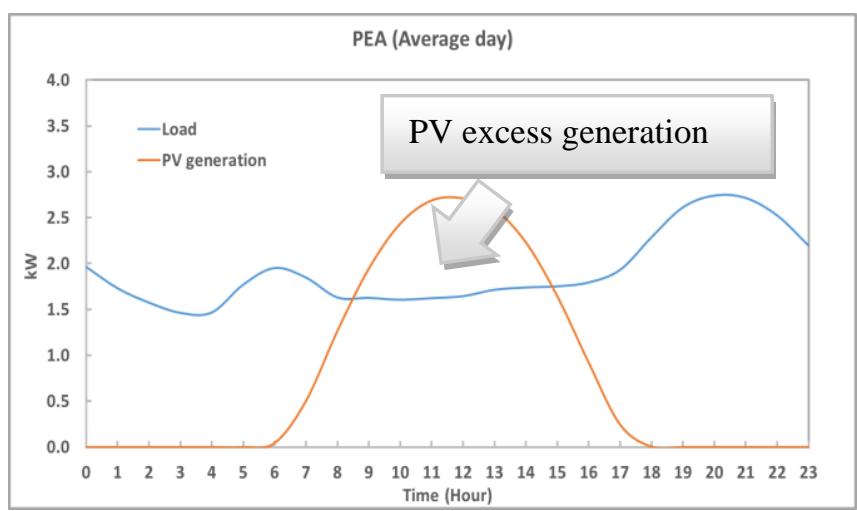

(b) PEA

Fig. 1. Household load profile and PV generation profile for MEA and PEA.

\section{COSTS AND BENEFITS OF HOUSEHOLD PV-BATTERY SYSTEMS TO UTILITIES IN THAILAND}

As discussed in [3], [10], rooftop PV installation would have both positive (benefit) and negative (cost) impacts on Thai utilities. When PV adoption is high, these benefits and costs become more relevant [3]. Typically, solar PV can help reduce net load demand of power system during daytime. In most cases, capacity value of solar is limited and decreases when the system peak load is shifted to night time, creating a "duck curve" as occurred in the California ISO (CAISO) and shown in Fig. 2. The difference of a duck curve from a normal load curve is that a duck curve shows (1) two periods of high demand (morning and late evening) and (2) low demand when rooftop PV generate electricity during the day. When there are higher shares of rooftop PV in the grid, the difference between minimum load and maximum load becomes very significant.

According to [12], a duck curve leads to concerns that there would be an over generation risk and high required ramp rate of power system in the morning and evening. There are two broad solutions to the duck curve: (1) "Fatten" the duck and (2) "Flatten" the duck. The former option is related to methods to increase the flexibility of power system, while the latter option becomes more relevant to this paper as the use of household battery can help "flatten" duck curve by storing PV excess generation during daytime and consume it in the evening.

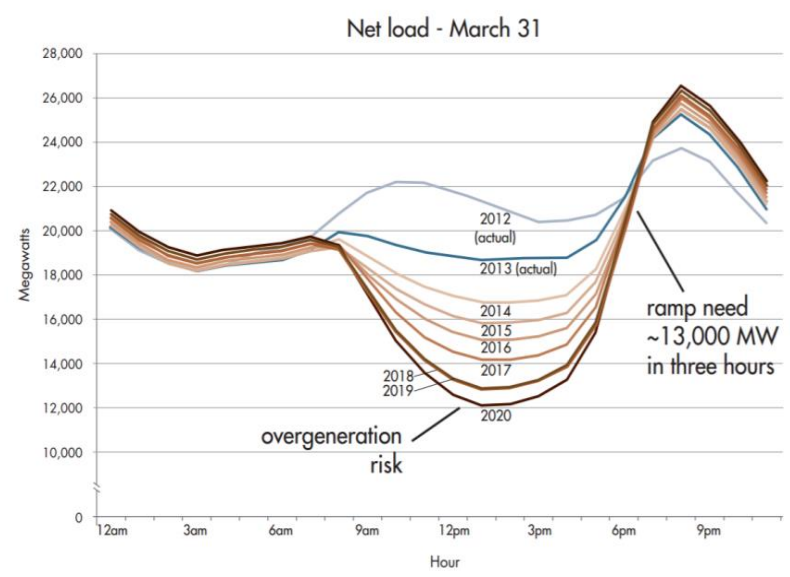

Fig. 2. The CAISO duck curve [11].

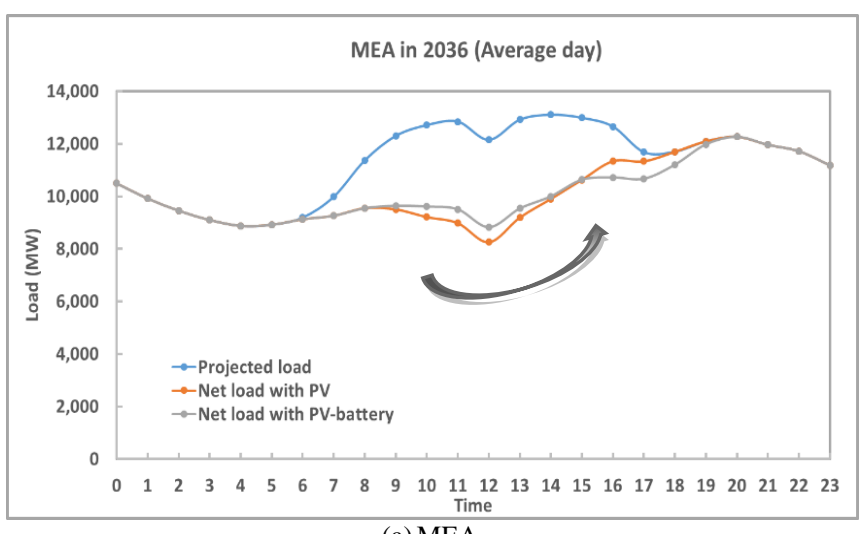

(a) MEA

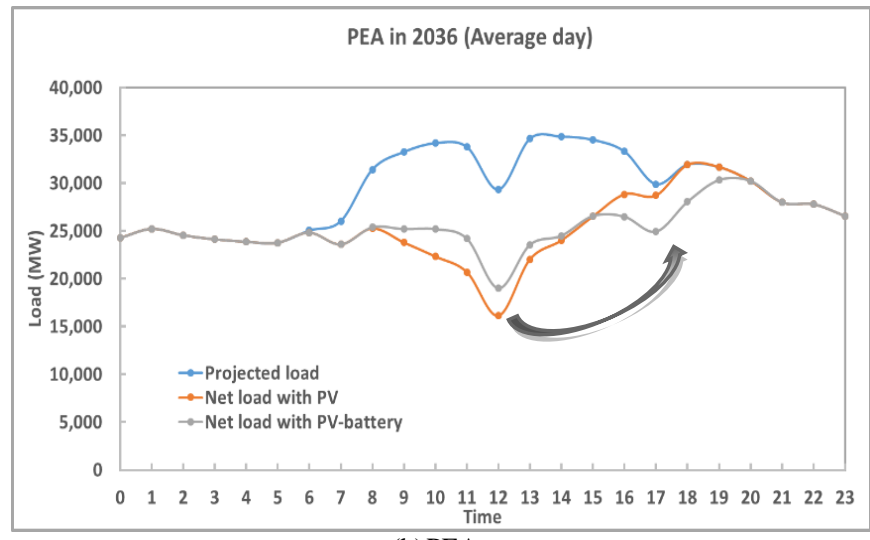

(b) PEA

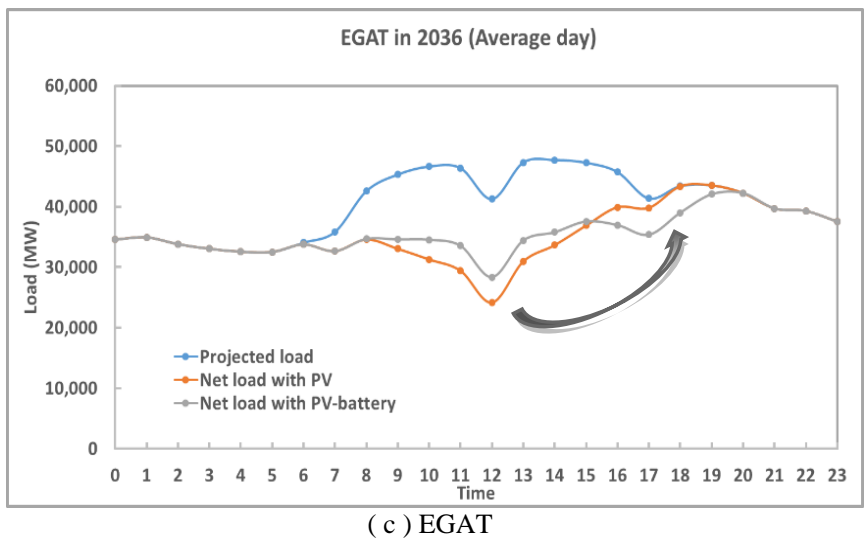

Fig. 3. Average system load profiles in 2036 faced by utilities in Thailand ${ }^{2}$.

${ }^{2}$ Net load with PV means all rooftop PV systems of all customer groups were assumed to get installed without battery. Net load with PV-battery means in 2018-2028, all customer groups were assumed to install PV-only system, while in 2029-2036, household customers were assumed to install PV-battery system and other customer groups were assumed to install PV-only system. 
Based on the selected PV adoption scenario ${ }^{3}$ from [3] and the preliminary results of customer economics of household PV-battery system that PV-battery system would be able to compete with PV-only system in at least around 10 years from now ${ }^{4}$ [3], average system load profiles in $2036^{5}$ faced by utilities in Thailand are illustrated in Fig. 3. It is clearly seen from all figures that the use of household batteries can "flatten" system load curves and mitigate the high ramp rate requirements. For instance, based on EGAT, the supply of power needs to be ramped up around $15,770 \mathrm{MW}^{6}$ in four hours $(12 \mathrm{pm}-4 \mathrm{pm})$ in the case of PV-only, while it would be around $8,600 \mathrm{MW}^{7}$ for PV-battery

Fig. 3c). Moreover, based on Fig. $3 b$ and $3 c$ for PEA and EGAT, the use of household batteries can not only flatten system load curves, but also reduce peak load in the evening (around 6-7 pm) compared to $\mathrm{PV}$-only case. It is not the case for MEA since assumed total PV installation is not high. Therefore, it is not enough to reduce peak load at night (around $8 \mathrm{pm}$; see Fig. 3a). The use of household batteries can also add additional solar capacity values to the power system. Particularly for EGAT, since the use of battery can reduce peak demand in the evening, it means that EGAT can also avoid the use of expensive fuel in the evening while PV-only systems can only do during daytime. Additionally, based on [13], the use of batteries can decrease PV integration cost and alleviate grid stability issues due to less PV surplus generation that would add another benefit of PV-battery installation to the power system.

In contrast, as the use of batteries can increase a PV self-consumption ratio of household, that implies higher revenue losses to distribution utilities (MEA and PEA). Also, distribution utilities cannot take benefits from buying PV excess generation at lower prices than wholesale rate and selling to other customers (re-sale of exported PV as discussed in [3]). These two components create negative economic impacts to distribution utilities in the country, while it is not the case for generation and transmission utilities (EGAT) as re-sale of exported electricity is not relevant to EGAT and there are unchanged revenue losses due to unchanged level of PV installation (only shifting the consumption of household PV excess generation from daytime to evening).

In summary (Fig. 4), for distribution utilities (MEA and PEA), the use of household batteries leads to (1) higher revenue losses as household customers increasingly self-consume their PV electricity and (2) lower re-sale of

\footnotetext{
${ }^{3}$ The PV adoption scenario includes $8 \mathrm{GW}$ for MEA, $25 \mathrm{GW}$ for PEA and $33 \mathrm{GW}$ for overal country in 2036. Focusing on household, there are $4 \mathrm{GW}$ for MEA, $17 \mathrm{GW}$ for PEA and $21 \mathrm{GW}$ fo overall country in 2036.

${ }^{4}$ Household customers were assumed to install PV-only system from 2018-2028 and in 2029-2036, they were assumed to install a battery together with PV as it can compete with PV-only 2029-2036, hey wiste system. A Li-ion baltory size was assumed to be $6.5 \mathrm{kWh}$. It was charged from $8 \mathrm{am}-3 \mathrm{pm}$ an discharged from 3pm onward. All PV electricity was set to meet load first before charging battery. For other customer groups (small-medium-large general service) were assumed to install PV withou battery every year.

Load growth was assumed to be around 3.5\% according to Thailand's Power Development Plan (PDP2015) and all other relevant assumptions can be found at [3].

${ }^{5}$ The year of 2036 was selected as it is the end of Thailand's Alternative Energy Development Plan (AEDP 2015-2036).

${ }^{6}$ From

Fig. 3c (PV-only; grey

line), EGATs loads are 24,153 MW and 39,921 at 12pm and 4pm, respectively. Thus, it would be $15,768 \mathrm{MW}$ needed to be ramped up in 4 hours.
}

exported PV as distribution utilities cannot buy lower-priced PV electricity to re-sale to other customers. On the other hand, the use of household batteries can (1) increase avoided cost of distribution capacity (increasing solar capacity values in order to defer some necessary investment due to increasing peak load) and (2) decrease PV integration cost. Therefore, in order to weight between positive and negative values of household battery use, it is necessary to carefully quantify each component.

For generation and transmission utility (EGAT), it is clear that the use of household batteries can add additional benefits to EGAT's system by (1) increasing avoided cost of generation/transmission capacity \& reserve (or increasing solar capacity values to EGAT); (2) increasing avoided cost of energy \& loss (increasing energy values to EGAT) and (3) lowering integration cost. Moreover, there is no additional cost to EGAT's system. As stated, EGAT's revenue losses are unchanged and re-sale of exported PV is not relevant to them. Thus, it would be implied that EGAT should get benefits from household battery uses. It is also worth noting that there are other cost and benefit components (i.e. avoided cost of loss, discussed in [3], [10] for MEA and PEA) that remain unchanged due to the use of household batteries and are not included in the discussion of this paper.
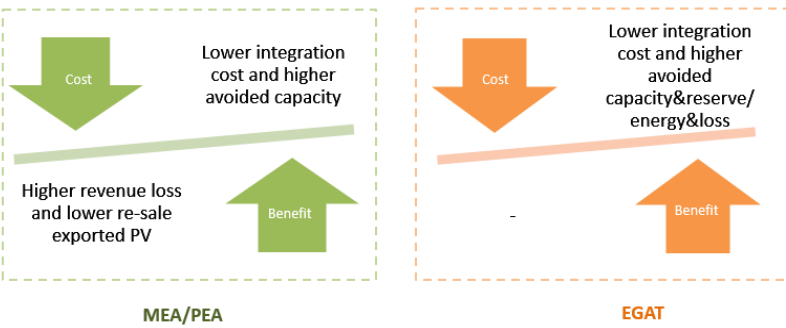

Fig. 4. Impacts of household PV-battery system to Thai utilities.

\section{CONCLUSION}

Driven by decreasing PV and battery cost and mismatch between household load profile and PV generation profile, household PV-battery systems are expected to be deployed in Thailand in near future. Thus, it is necessary for Thai utilities to understand their economic impacts on power system. Clearly, the use of household battery can increase solar capacity values and energy values to power system and reduce $\mathrm{PV}$ integration cost as some of $\mathrm{PV}$ electricity can be stored in the battery during daytime and consumed in the evening. It is also important to note that this situation will occurs only when household batteries are operated in a "system friendly manner", which means their dispatch energy model needs to be set as discussed in this paper. On the other hand, the inclusion of household batteries leads to higher PV self-consumption ratio, implying that there are additional revenue losses and reduced benefits of re-sale of exported PV for distribution utilities. Thus, it is worth quantifying each cost and benefit component to understand the value of battery to power system in order to adopt future policy supports and find out mitigation approaches around 8,602 MW needed to be ramped up in 4 hours. 
effectively as currently conducting in [3] .

\section{REFERENCES}

[1] A. Chaianong and C. Pharino, "Outlook and challenges for promoting solar photovoltaic rooftops in Thailand," Renewable Sustainable Energy Reviews, vol. 48, pp. 356-372, 2015.

[2] GIZ-Deutsche Gesellschaft für Internationale Zusammenarbeit, "Thailand solar PV policy update 01/2017," Federal Ministry for Economic Affairs and Energy, Bangkok, 2017.

[3] A. Chaianong, "Cost-benefit analysis and implication of differen rooftop PV systems with and without energy storages on Thai utilities and ratepayers," On-going $\mathrm{PhD}$ dissertation, The Joint Graduate School of Energy and Environment, King Mongkut's University of Technology Thouburi, Bangkok, Thailand.

[4] J. Hoppmann, J. Volland, T. S. Schmidt, and V. H. Hoffmann, "The economic viability of battery storage for residential solar photovoltaic systems-A review and a simulation model," Renewable and Sustainable Energy Reviews, vol. 39, pp. 1101-1118, 2014.

[5] IRENA-International Renewable Energy Agency, "Battery storage for renewables: Market status and technology outlook," 2015.

[6] N. Kittner, F. Lill, and D. M. Kammen, "Energy storage development and innovation for the clean energy transition," Nature Energy, vol. 2, 2017.

[7] O. Schmidt, A. Hawkes, A. Gambhir, and I. Staffell, The Future Cost of Electrical Energy Storage Bases on Experiences Rates, vol. 2, 2017.

[8] I. S. E. Fraunhofer, "Levelized cost of electricity renewable energy technologies," Freiburg, 2018

[9] A. Chaianong, S. Tongsopit, A. Bangviwat, and C. Menke, "Bill saving analysis of rooftop PV customers and policy implications for Thailand," Renewable Energy, vol. 131, pp. 422-434, 2019.

[10] A. Chaianong, A. Bangviwat, and C. Menke, "A framework for evaluating economic impacts of rooftop PV systems with or without energy storage on Thai distribution utilities and ratepayers," IOP Conference Series: Earth and Environmental Science, 2017.

[11] California ISO. (2018). Fast facts [Online]. Available: https://www.caiso.com/documents/flexibleresourceshelprenewables_f astfacts.pdf

[12] P. Denholm, M. O. Connell, G. Brinkman, and J. Jorgenson, "Overgeneration from solar energy in California: A filed guide to the duck chart," National Renewable Energy Laboratory, Golden, CO, 2015.
[13] Solar Trade Association. (2018). [Online]. Available https://www.solar-trade.org.uk/new-analysis-shows-low-cost-integrati ng-solar-power-system

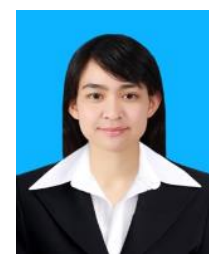

Aksornchan Chaianong was born in 1990 and received B.Eng. degree in chemical engineering from Chulalongkorn University and B.B.A. degree from Ramkhamhaeng University, Bangkok, Thailand, and she completed M.Sc. degree in energy and earth resources from the University of Texas at Austin, Austin, Texas, USA in 2015.

She is a $\mathrm{PhD}$ candidate in energy technology at the Joint Graduate School of Energy and Environment (JGSEE), King Mongkut's University of Technology Thonburi, Bangkok, Thailand. Her research focuses on issues in renewable energy policy, electricity market and future utility.

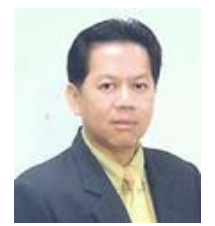

Athikom Bangviwat has educational background in mechanical engineering and economics. He obtained B.Eng. and M.Eng. from Chulalongkorn University, B.Econ, from Ramkhamhaeng University, and M.Econ. from Thammasat University, Bangkok, Thailand. $\mathrm{He}$ completed his $\mathrm{Ph} . \mathrm{D}$. in mechanical engineering at University of Houston, Houston, Texas, USA in 1987. He has extensive working experiences in industry, finance and education He gained his experiences in oil and electricity industries, and also financial business before joining the Joint Graduate School of Energy and Environment (JGSEE), King Mongkut's University of Technology Thonburi, Bangkok, Thailand in 2007. His areas of research interest are energy policy \& management, combined heat and power, electricity for community.

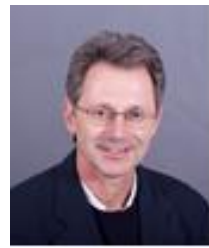

Christoph Menke was born in 1956 and received the Master degree in mechanical engineering from Technical University of Braunschweig, Germany in 1983 and the Dr. Ing. degree in mechanical engineering /energy from Technical University of Braunschweig, Germany in 1989. He is a full-time professor at Trier University of Applied Sciences, Germany since 1997 and a distinguished professor at the Joint Graduate School of Energy and Environment (JGSEE), King Mongkut's University of Technology Thonburi, Bangkok, Thailand since 2013. 